\title{
Long-term PIT tag retention rates in Atlantic salmon (Salmo salar)
}

\author{
Anders Foldvik* ${ }^{*}$ and Eli Kvingedal
}

\begin{abstract}
Background: Passive integrated transponder (PIT) tags are widely used in studies of various aspects of fish survival, movement and behaviour. Quality of such studies depends on the fish retaining the tags over the study period and that the tagging procedure or the tag does not influence behaviour or survival. Here we document PIT tag retention rates in hatchery-reared Atlantic salmon over a 533-day period from the late juvenile freshwater stage (pre-smolts) to young adults after 1 year in seawater. Fish were marked with 12-mm PIT tags, injected into their body cavity, as age $1+$ pre-smolt and scanned for presence of PIT tags five times during the study.

Results: Tag retention for the entire period was $91 \%$ and varied between periods (96.09-99.89\%). For individual time steps, daily retention rate was lowest in the first period following tagging (days $0-49$ ). After this period retention rate increased substantially, before again dropping close to initial levels at the two last periods (days 173-533). Length of fish was only significantly related to retention during the first period. No difference in retention rates was found between males and females. A subset of fish without detected tags was X-rayed to verify that lack of PIT detection was due to tag loss.

Conclusion: The retention rates observed in this study clearly show that tag loss needs to be accounted for when analysing PIT tag data on Atlantic salmon. Further, the temporal changes in retention rate clearly challenge previous assertions that tag loss is something that primarily occurs shortly after tagging or during spawning.
\end{abstract}

Keywords: Biotelemetry, PIT tagging, Tag retention, Tag loss

\section{Background}

Since 1980s, the use of PIT tags to study or monitor various aspects of behaviour or survival of anadromous salmonids has increased substantially [1]. For markrecapture studies aimed at studying dispersal, migration or survival, information regarding tag retention and failure rates is important for interpretation of results. PIT tag retention rates have been shown to vary among species, and even within species depending on life stage, sex or tag placement $[2,3]$. Despite the wide use of PIT tags in both laboratory experiments, field studies and population monitoring of Atlantic salmon, we are not aware of any published information on long-term retention of PIT tags spanning juvenile to adult life stages. For other species of Salmonidae PIT tag retention rates have been

*Correspondence: anders.foldvik@nina.no

Aquatic Department, Norwegian Institute for Nature Research,

Høgskoleringen 9, 7034 Trondheim, Norway published covering longer time periods and life stages from both fresh water resident [3-5] and anadromous [6] populations. Studies of long-term retention ( $>1$ year) have been exclusively conducted in natural settings, making frequent recaptures to determine temporal trends in retention rates difficult for fresh water resident populations and impossible for anadromous populations during the ocean phase of their life. A higher number of studies have investigated tag retention in hatchery conditions, allowing temporal patterns in tag loss to be assessed [7]. These studies are, however, mostly conducted over short time periods (1-2 months) or for a single life stage. Results from the studies of long- and short-term retention rates and experiences from other types of surgically implanted transmitters [8] have led to the assertion that tag loss mainly occurs shortly after tagging for juvenile fish and during spawning for adults. The importance of correcting obtained survival, abundance and dispersal 
estimates has previously been stressed by among others Bateman [4]. Anadromous salmon from a single cohort can have variation of several years in both time spent in the river as juveniles and as adult in the ocean [9]. This means that for salmon tagged as juveniles, correction of survival estimates requires knowledge on temporal patterns in tag retention rates. Here we present data on temporal changes in retention rates over a period relevant for studies of wild one-sea winter Atlantic salmon.

\section{Methods}

In April 2016, 2986 age 1+ hatchery-reared Atlantic salmon pre-smolt were tagged with 12.5 -mm PIT tags (Biomark HPT12) for unique fish identification in a study investigating changes in specific physical characters from pre-smolt to adults. Tags were inserted to the body cavity using a Biomark gun implanter with pre-loaded needles. Fish were anesthetized using benzocaine (20\%) $1.5-2 \mathrm{ml} / 10 \mathrm{l}$. The fish were kept in a large indoor tank for 533 days and scanned with a handheld reader (Biomark 601) for the presence of PIT tags 5 times during this period. Number and timing of samplings were limited by the Norwegian Food Safety Authority based on animal welfare considerations. At each scanning event, fish were measured for fork length $\left(L_{\mathrm{F}}\right)$ and individuals without detected PIT tags were removed from the experiment and euthanized using an overdose of anaesthetics (benzocaine $20 \%, 40 \mathrm{ml} / 10 \mathrm{l}$ ). In total, three individuals without PIT tags were accidentally returned to the tank, but these were subtracted from the counted number before calculating retention rates of the next scanning. During the fourth scanning event, 1146 fish with tags were killed using an overdose of anaesthetics and their sex determined by opening the fish. Removal of these fish was conducted to avoid negative animal welfare effects of increased biomass in the tanks as fish grew. Fish without detected tags from the fourth scanning were X-rayed, before being sexed, to check if lack of detection was due to tag loss or tag failure. Fish without detected tags in the fifth scanning were also sexed. Fish that died between samplings were not systematically scanned; hence, PIT retention rates are only calculated from the population of fish in the tank at the time of sampling.

\section{Results}

The experiment started with 2986 fish, and during the entire period PIT tags were not detected in 191 fish (Table 1). Unfortunately, data on tag status of dead fish removed from the tank between scannings were not recorded. The PIT tag retention rate for the entire period, calculated as the product of the retention rates found at each sampling, was $91 \%$. Retention rates between samplings ranged from 96.09 to $99.89 \%$. Corrected for the length of time between samplings (Table 2), daily retention rates were lowest in the period from initial tagging to the first scanning (days 0-49), and highest in the following two periods (days 49-90 and 90-173). During the two last periods (days 173-358 and 358-533), retention rates decreased again to the same level as from tagging to the first scanning. Pairwise test of differences in daily loss rates (Table 2) shows that the loss rates in the last two periods did not differ significantly from the initial period (exact rate ratio test, $p=0.50$ and $p=0.42$ ). Among the fish dying in the tank in the last period, one out of 37 individuals lacked tag. Including these fish in estimated retention rate of the last sampling hardly affects the estimate (95\% confidence interval from 95.26-96.81 to $95.29-96.82 \%)$. Comparing the sex ratio of fish that lacked tags on the fourth scanning event to the population sex ratio (Table 3) did not reveal any significant differences $\left(X^{2}(1)=1.25, p=0.26\right)$. Neither on the last sampling occasion was the sex ratio significantly different from the population estimate $\left(X^{2}(1)=0.11, p=0.74\right)$. Here, 12 of the 24 females without tags were sexually mature. In the fish without detected tags from the fourth scanning, X-rays revealed no PIT tags. The mean length

Table 1 Sampling schedule with data on lost tags and body size

\begin{tabular}{|c|c|c|c|c|c|c|c|c|c|}
\hline Handling & Date & $N_{\text {total }}$ & $N_{\text {lost }}$ & $R(\%)$ & $L_{\text {total }}(\mathrm{mm})$ & $L_{\text {lost }}(\mathrm{mm})$ & $\mathrm{DL}(\mathrm{mm})$ & $p$ & Life stage \\
\hline Tagging & 05.04 .2016 & 2986 & & & $163.2 \pm 19.6$ & & & & Pre-smolt (fw) \\
\hline First sampling & 24.05 .2016 & 2908 & 35 & 98.80 & $185.6 \pm 20.3$ & $177.1 \pm 27.9$ & $-8.5 \pm 3.5$ & $<0.05$ & Smolt (sw) \\
\hline Second sampling & 04.07.2016 & $2721^{a}$ & $7^{\mathrm{a}}$ & 99.78 & $207.0 \pm 22.1$ & $202.4 \pm 8.8$ & $-4.6 \pm 3.5$ & n.s. & Postsmolt (sw) \\
\hline Third sampling & 25.09.2016 & 2643 & 3 & 99.89 & $272.3 \pm 28.0$ & $279.3 \pm 3.7$ & $7.0 \pm 16.2$ & n.s. & Postsmolt/adult (sw) \\
\hline Fourth sampling & 29.03 .2017 & 2533 & 99 & 96.09 & $373.0 \pm 36.7$ & $379.5 \pm 29.9$ & $6.5 \pm 3.7$ & n.s. & Adult (sw) \\
\hline Fifth sampling & 20.09.2017 & $1286^{b}$ & $47^{b}$ & 96.50 & $449.7 \pm 41.4$ & $445.1 \pm 41.6$ & $-4.6 \pm 6.2$ & n.s. & Adult (sw) \\
\hline
\end{tabular}

Total number of fish $\left(N_{\text {total }}\right)$, number of fish without PIT tag $\left(N_{\text {lost }}\right)$, proportion of fish with tag $(R)$, fork length (average \pm SD) of all fish $\left(L_{\text {total }}\right)$ and fish without tag $\left(L_{\text {lost }}\right)$, and estimated difference in length (DL; average $\pm S E$ ) followed by the test result $(p)$. Freshwater (fw) and saltwater (sw) indicated for the life stages

a Includes one individual with lost tag from the previous sampling

b Includes two individuals with lost tag from the previous sampling 
Table 2 Retention and loss rates for each period

\begin{tabular}{lcllll}
\hline Handling & Days & $\boldsymbol{R}(\%)$ per day & Loss (\%) per day & IndYears & Loss per IndYears \\
\hline First sampling & 49 & 99.975 & 0.0246 & 390 & $0.090^{\mathrm{a}}$ \\
Second sampling & 90 & 99.995 & 0.0054 & 306 & $0.020^{\mathrm{b}}$ \\
Third sampling & 173 & 99.999 & 0.0014 & 601 & $0.005^{\mathrm{b}}$ \\
Fourth sampling & 358 & 99.979 & 0.0211 & 1284 & $0.077^{\mathrm{a}}$ \\
Fifth sampling & 533 & 99.980 & 0.0200 & 616 & $0.073^{\mathrm{a}}$ \\
\hline
\end{tabular}

Number of days from tagging to sampling (days) with parameters describing retention and loss rates in each period: proportion of fish retaining their tag ( $R$ ) scaled with time, proportion of fish with lost tags (loss) scaled with time, number of fish multiplied with time in years (IndYears), and number of lost tags per individual and years with a letter denoting rates significantly different at a 0.05 significance level

Table 3 Sex distribution in a population sample and the lost tag group

\begin{tabular}{lllllllll}
\hline Date & $\boldsymbol{N}_{\text {sample }}$ & $\boldsymbol{M}_{\text {sample }}$ & $\boldsymbol{F}_{\text {sample }}$ & $\mathbf{S R}_{\text {sample }}$ & $\boldsymbol{N}_{\text {lost }}$ & $\boldsymbol{M}_{\text {lost }}$ & $\boldsymbol{F}_{\text {lost }}$ & $\mathbf{S R}_{\text {lost }}$ \\
\hline 29.03 .2017 & 1083 & 519 & 564 & 0.92 & 99 & 53 & 46 & 1.15 \\
20.09 .2017 & & & & & 47 & 20 & 24 & 0.83 \\
\hline
\end{tabular}

Number of males $(M)$, females $(F)$ and sex ratio $(\mathrm{SR})$ in the total sample $\left(N_{\text {sample }}\right)$ and among fish with lost tags $\left(N_{\text {lost }}\right)$

of fish that had retained the tags was significantly different from the group that had lost their tags only at the first scanning, with the latter being smaller $(t=2.45$, $d f=2941, p=0.014)$.

\section{Discussion}

Observed tag retention rates of 12.5-mm PIT tags implanted in the body cavity of Atlantic salmon over a 533 -day period was $91 \%$. As expected from previous studies, daily tag retention rates were lowest in the period following marking (day 0-49) and then increased during the next two periods (days 49-90 and 90-173). Unexpectedly, tag retention rates during the two last and longest periods (days 173-358 and 358-533) of the experiments decreased again to levels close to the rates immediately after tagging. Low PIT tag retention rates of larger fish in studies of other Salmonidae species have been ascribed to tag loss during spawning [2-5]. As the experiment was ended before fish were ready to spawn, this was not a factor affecting our results. Sex ratio of fish shedding their marks during the fourth and fifth period did not significantly deviate from the population sex ratio. Of the 24 females with lost tags after the fifth period, 10 had well-developed ovaries and would have been ready to spawn a month or two later. In addition to tag expulsion with eggs, there are several ways tags can exit the fish: through the incision, through the body wall and through the intestine [8]. Atlantic salmon have two abdominal pores located close to the anus that connect directly to the body cavity [10]; these might also be potential exits. Our impression is that incisions were healed at the first scanning, making this a likely exit route only during the first period after tagging. Visual inspection of fish without tags from the fourth and fifth scanning did not reveal any obvious signs of tags having exited through the body wall. Within periods, we only found PIT tag retention rate to be significantly influenced by fish size during the first period after tagging, with smaller fish having lower retention rates. Size-dependent retention rates of PIT tags have previously been reported for juvenile stages of brown trout (S. trutta) [11] and steelhead trout (Oncorhynchus mykiss) [12]. The tag retention rates found in this study are similar to those reported by Knudsen et al. [6] on juveniles Chinook salmon (Oncorhynchus tshawytscha) over durations of 1-2 months (98\%), but higher than for adults in the same study (82\%) over durations ranging from 18 months to 4 years.

Absence of tags was verified in 99 of the fish using $\mathrm{X}$-ray, indicating that tag failure is not likely to be influencing the results. As absence was not verified in all fish, tag failure cannot be ruled out. Tag retention rates could be affected by the environment the fish are kept in, such as temperature effects on healing speed of incision wounds in the initial period after tagging [2]. Hatchery fish, given high-fat food, often deposit large amount of fat in their abdominal cavity. This could possibly increase the risk of tag encapsulation and later shedding through the intestine or the body wall. Hence, we cannot rule out that the hatchery environment itself or stress from repeated handling has affected the retention rates found in this study. Further, that sex and tagging status were not systematically recorded in the fish that died between samplings, could affect results. The retention rate for fish 
that died between the last two samplings does not bias the retention rate estimate for the last period, however.

The results from this experiment show that PIT tag retention rates need to be included in analysis of longterm studies or monitoring of Atlantic salmon. Assuming negligible tag loss after the healing of incision wounds can potentially lead to underestimation of survival or population size. We concur with previous studies [2-4] that retention rates should be assessed directly in field studies, either by implanting two PIT tags in different body parts or using PIT tags in combination with other marking methods such as coded wire tags, elastomer marks, fin clipping. If direct assessment of retention rates is not possible, inclusion of ranges of retention rates from the literature in modelling or analysis should be considered.

The duration of, and changes in life stages covered by this experiment, makes the results especially relevant for research and population monitoring of wild Atlantic salmon populations. We hope our findings will be valuable during assessment of results from studies of PITtagged Atlantic salmon and assist planning of future studies.

\section{Abbreviations}

PIT: passive integrated transponder; FL: fork length.

\section{Authors' contributions}

AF and EK designed and carried out the experiment. Both authors analysed the data and contributed to the text, and read and approved the final manuscript.

\section{Acknowledgements}

We are grateful to the staff at the Norwegian Institute for Nature Research Station at Ims, and especially Steffen Johnsen, for technical assistance during the study. We would also like to thank Frank Jakobsen, Eva Ulvan, Randi Saksgård and Johan Henrik Hårdensson Berntsen for help with all handling of the fish and recording of the data.

\section{Competing interests}

The authors declare that they have no competing interests.

\section{Availability of data and materials}

All data generated or analysed during this study are included in this published article.
Ethics approval and consent to participate

This experiment was approved by the Norwegian Food Safety Authority, FOTS ID 8409.

\section{Funding}

This work was partly funded by the Norwegian Research Council.

\section{Publisher's Note}

Springer Nature remains neutral with regard to jurisdictional claims in published maps and institutional affiliations.

Received: 10 November 2017 Accepted: 6 March 2018

Published online: 20 March 2018

\section{References}

1. Drenner SM, et al. A synthesis of tagging studies examining the behaviour and survival of anadromous salmonids in marine environments. PLOS ONE. 2012;7(3):e31311.

2. Dieterman DJ, Hoxmeier RJH. Instream evaluation of passive integrated transponder retention in brook trout and brown trout: effects of season, anatomical placement, and fish length. North Am J Fish Manag. 2009:29(1):109-15.

3. Mamer ERJM, Meyer KA. Retention rates of passive integrated transponder tags, visible implant elastomer tags, and maxillary marks in wild trout. North Am J Fish Manag. 2016;36(5):1119-24.

4. Bateman DS, Gresswell RE, Berger AM. Passive integrated transponder tag retention rates in headwater populations of coastal cutthroat trout. North Am J Fish Manag. 2009;29(3):653-7.

5. Meyer KA, et al. Retention of passive integrated transponder tags in stream-dwelling rainbow trout. North Am J Fish Manag. 2011;31(2):236-9.

6. Knudsen $\mathrm{CM}$, et al. Effects of passive integrated transponder tags on smolt-to-adult recruit survival, growth, and behavior of hatchery spring Chinook salmon. North Am J Fish Manag. 2011;29(3):658-69.

7. Richard $\mathrm{A}$, et al. Effects of passive integrated transponder tagging methods on survival, tag retention and growth of age-0 brown trout. Fish Res. 2013;145:37-42.

8. Jepsen $\mathrm{N}$, et al. Surgical implantation of telemetry transmitters in fish: how much have we learned? Hydrobiologia. 2002;483:239-48.

9. Thorstad EB, et al. Aquatic nomads: the life and migrations of the Atlantic salmon. In: Aas $\varnothing$, et al., editors. Atlantic salmon ecology. Oxford: WileyBlackwell; 2011.

10. Bruno DW, Noguera PA, Poppe TT. A colour atlas of salmonid diseases Berlin: Springer; 2013.

11. Acolas ML, et al. Laboratory experiment on survival, growth and tag retention following PIT injection into the body cavity of juvenile brown trout (Salmo trutta). Fish Res. 2007;86(2-3):280-4.

12. Hill MS, et al. Development and evaluation of portable PIT tag detection units: PITpacks. Fish Res. 2006;77(1):102-9.

Submit your next manuscript to BioMed Central and we will help you at every step:

- We accept pre-submission inquiries

- Our selector tool helps you to find the most relevant journal

- We provide round the clock customer support

- Convenient online submission

- Thorough peer review

- Inclusion in PubMed and all major indexing services

- Maximum visibility for your research

Submit your manuscript at www.biomedcentral.com/submit 